and paratyphoid fever rose after the military operations, but outbreaks had been limited to relatively few communities. The peak was reached in January 1944, when more than a million new cases were reported; but the outbreak was controlled so quickly that only 39 cases were reported during the last week of February 1944. Typhus had not yet been a problem in north-west Europe. Two outbreaks of smallpox had occurred in Italy, but none in north-west Europe. In February 1944, measures for the control of malaria were inaugurated in south and central Italy.

The United States War Department announced, on October 4, that tetanus had been virtually eliminated from the United States Armed Forces by compulsory immunization of all officers and men. No case had been reported among completely immunized troops, but a handful of cases had occurred when immunization had not been complete. Up to September 15, 1944, no cases had occurred in the United States Navy, which also requires cotnpulsory immunization. Brigadier-General R. W. Bliss, assistant surgeon general, United States Army, said that, during a recent tour of the Pacific War theatre, he did not see one mosquito or fly. "When we first took over the Pacific Islands," he said, "there were clouds of insects everywhere, actually making it difficult to see. To-day, if we locate one mosquito, we consider it comparable to finding a four-leaf clover. To me, that's the outstanding achievement of medical science in this war." There were no malaria-carrying mosquitoes in Saipan, but there were species which carried dengue fever. After a few weeks of insect control, dengue fever, of which there had been a great many cases, practically disappeared. Medical sanitary companies divided the island into squares and drained and filled in swamps constantly. "The amazing D.D.T. insecticide, which did such a wonderful job in controlling typhus in Naples, was sprayed by hand and by planes."

\section{Birds in Agriculture}

DeFinite evidence on bird behaviour is ever valuable, especially as regards agriculture, and Mr. A. Roebuck, of the Midland Agricultural College, has done well to put on record in the form of a leaflet five cases in which birds gave help to the farmer ("Birds in Agriculture." By A. Roebuck. Midland Agricultural College, Sutton Bonington). Rooks, lapwings and blackheaded gulls were the species that in these instances did much good work with regard to wireworms (Agriotes obscurus), dungbeetles (Aphodius pinetarius and $A$. inquinatus), leatherjackets (Tipula paludosa) and cutworms (Agrotis segetum). Of course, it has long been known that these birds take such agricultural pests, but here we have facts lucidly set forth that show how useful they are in the economy of the farm.

\section{Empiricism and Descartes' Dream Situation}

THE problem of determining the status of empirical propositions continues to exercise the minds and engross the attention of philosophers more than any other philosophical problem. The easy solutions of the logical positivists are being slowly torn to pieces by the more leisurely consideration of philosophers who, while sympathetic towards the general attempt to distinguish among propositions between the empirical sheep and the metaphysical goats, are yet suspicious of the ways of doing it. The attempt to find an empirical content for all genuine propositions gives rise to a number of problems. In the seventeenth century, Descartes had expressed the view that as the senses sometimes deceive, they might do so always. Therefore he concluded that he might be dreaming, no matter how wide awake he seemed to himself to be. Can one maintain this position without self-contradiction?

In a paper "On the Relation of some Empirical Propositions to their Evidence" (Mind, Oct. 1944), Mr. C. Lewy discusses whether it is self-contradictory to say that "I have all the evidence which I do have for saying that I am not now dreaming, and however many tests I may make in the future, they will all confirm this evidence, but I am now dreaming" (p. 289). The paper is long, subtle and difficult to follow. The point of the discussion, when reached, consists in the author's showing that the first part of the statement quoted makes the demand that all the evidence that turns up should be positive, whereas the second part demands at least one piece of negative evidence. There could not be a situation which fulfilled these two conditions. The author concludes not, as might be expected, that the statement is self-contradictory, but that to the question whether it is or not, no answer is possible.

\section{Fixing Confidence Limits to Measurements}

IN a paper read in London by H. J. Josephs before the Institution of Electrical Engineers on January 19, the author discusses the problems involved in the application of simple tests of significance to small sets of measurements. The paper opens with an account of the $w$-test, which applies to normally distributed variables, and this is followed by a description of the $t$-test, which is of particular use in dealing with a small number of observations. A method of rapidly applying this test is given, and it is shown that if the true mean value of a physical quantity is unknown, the confidence limits to be attached to an estimated value obtained from the measurements may be determined easily. A quick method is described of estimating the standard deviation of a set of measurements, and it is shown that for very small samples the extreme-mean or median forms a good alternative to the arithmetic mean and is often easier to calculate. Pearson's $\chi^{2}$ test of goodness-of-fit is explained and illustrated, emphasis being placed on the flexible nature of this test and its relationship to the $w$-test. The elementary tests of significance described involve only a small amount of simple arithmetic, so that they enable an engineer to replace guesses or tentative estimates by well-founded probabilities, and to assess the reliability of some of his results. No mention is made in the paper of the design of large-scale experiments, for which these simple tests are of value in rapidly analysing the data obtained from preliminary trials.

\section{Earth Tremor of December 30, 1944, in Britain}

A considerable. number of personal experiences of the earth tremor have now been received, and it appears that in some places the tremor reached intensity 5 on the modified Mercalli scale (Nature, Jan. 6, p. 15). In Yorkshire, the intensity was greatest in an elongated area near Skipton, and the only damage reported in this county was one chimney which developed a crack, possibly as the result of the shock, and had to be felled. An inquiry has 
been made concerning possible sounds associated with the tremor, and three definite observations have been made, all supported by independent observation. (1) A rumble : typical observation by Dr. J. R. Ashworth, of Rochdale, who writes, "I heard a very audible rumble accompanying the swaying movement of the house". (2) A sound like a rushing wind, often said to have been followed by a thud, all taking place at the same time as the swaying. (3) No sound: this was the experience of many who felt the tremor and "knew it could not be bombs because there was no sound". So far, no systematic geographical distribution of the observations of the different types is apparent. In one area observations of all three types were reported. Miss E. F. Bellamy, of the University Observatory, Oxford, felt the earth tremor; but the seismograph at the Observatory was not working at the time. The tremor was not recorded on the disk of the Jagger shock recorder belonging to the British Association, then and now working at Comrie. The tentative reading of the record of the tremor obtained by Mr. E. W. Pollard at Binstead, Isle of Wight, shows that it recorded at $00 \mathrm{~h} .36 \mathrm{~m}$. 27s. G.M.T., and Mr. Pollard remarks that the record he obtained was similar to those resulting from "a tank passing at 100 yds., (2) a submarine depth charge at 5 miles, (3) the Burton explosion". No news has yet been received of any possible recordings by seismographs outside the British Isles.

\section{Report of Seismological Investigations Committee}

THIs Committee of the British Association has just issued its report for 1944. This is its forty-ninth report, and it first records with regret the death of Dr. F. J. W. Whipple, who was chairman of the Committee during 1931-39. It is remarked that Whipple was primarily responsible for the leading place which Kew took in seismology, and it was also due in no small measure to his interest, enthusiasm and skill that the International Seismology Summary (published at Oxford) received such generous support from the International Geodetic and Geophysical Union. During the year there has been no alteration in the location or working of the instruments belonging to the Committee which are out on loan. The Milne-Shaw seismographs are at Oxford, Cape Town, Perth (Western Australia), Edinburgh and Fiji. There is also a clock at Fiji and a Jagger shock recorder at Comrie. Thanks are expressed to the collaborators. Two complete recording units have been dispatched to Bombay, and three spare clocks to Poona. Four Milne-Shaw seismographs are under construction for Bombay. Under war conditions, the preparation and publication of the International Seismological Summary is the sole responsibility of Miss E. F. Bellamy of the University Observatory, Oxford. The first quarter for 1935 has been published and partially distributed, while the computation is complete to the end of July 1935.

\section{Committee on Aids for the Deaf}

Ir has been announced in the House of Commons that the following committee has been appointed to advise and assist the Medical Research Council in promoting research into electro-acoustical problems relating to the design and application of instruments in alleviation of deafness: Dr. W. G. Radley (chairman), Mr. E. J. Barnes, Sir Lawrence Bragg, Mr. N. Fleming, Dr. C. S. Hallpike, Mr. L. C. Pocock and Dr. T. S. Littler (secretary). The Committee has formulated a detailed programme of research, and investigations in which physicists are collaborating with otologists and physiologists are in progress.

\section{Linear Intercepts, Areas and Volumes}

In the two theorems stated by S. I. Tomkeieff in a communication under this title in Nature of January 6 , p. 24, the word "by" was printed instead of "to". The theorems should read as follows :

"1. The average linear intercept of a convex polygon circumscribed to a circle is equal to the average linear intercept of the circle.

" 2 . The average linear intercept of a convex polyhedron circumscribed to a sphere is equal to the average linear intercept of the sphere."

\section{The Night Sky in February}

New moon occurs on Feb. 12d. 17h. 33m. U.T. and full moon on Feb. $27 \mathrm{~d}$. $00 \mathrm{~h} .07 \mathrm{~m}$. The following conjunctions with the moon take place: Feb. 1d. $03 \mathrm{~h}$., Jupiter $4^{\circ}$ N. ; Feb. 10d. $22 \mathrm{~h}$., Mars $0 \cdot 1^{\circ} \mathrm{S}$. ; Feb. 15d. 20h., Venus $8^{\circ}$ N. ; Feb. 2ld. 21h., Saturn $0 \cdot 6^{\circ}$ N. ; Feb. 28d. 06h., Jupiter $3^{\circ} \mathrm{S}$. The following occultations of stars brighter than magnitude 6 take place: Feb. 19d. 18h. 24.4m., $\delta$ Taur. $(D)$; Feb. 19d. 19h. 14.2m., 64 Taur. $(D)$; Feb. 19d. $20 \mathrm{~h}$. $09 \cdot 6 \mathrm{~m} ., 68$ Taur. $(D)$; Feb. 23 d. 2 h. $36 \cdot 8 \mathrm{~m}$., 63 Gemi. (D). The times refer to the latitude of Greenwich and $D$ refers to disappearance. Mercury rises at $7 \mathrm{~h} .04 \mathrm{~m}$. at the beginning of the month and is not well placed for observation; on Feb. 28 the planet is in superior conjunction when it rises at $7 \mathrm{~h} .07 \mathrm{~m}$. Venus is an evening star and sets at $21 \mathrm{~h}$. $10 \mathrm{~m}$. and 21h. $53 \mathrm{~m}$. at the beginning and end of the month respectively. Mars is too close to the sun for favourable observation. Jupiter can be seen throughout the night, rising at $20 \mathrm{~h} .54 \mathrm{~m}$. and $18 \mathrm{~h} .48 \mathrm{~m}$. at the beginning and end of the month respectively. Saturn sets at 5 h. $41 \mathrm{~m}$. on Feb. 1 and at $3 \mathrm{~h} .52 \mathrm{~m}$. on Feb. 28.

\section{Announcements}

Prof. Harold Laski will deliver the first public lecture of the British Association of Chemists at the Caxton Hall, Westminster, on February 14, at 6.30 p.m. His subject will be "The Place of the Scientist in Post-War Administration". Anyone who is interested is invited to attend.

THe Maharaja of Travancore Lord Curzon Prize of the University of Madras has been awarded this year to Mr. S. Rajagopalan of the Indian Institute of Science, Bangalore, for his thesis "Essays in Chemotherapeutical Synthesis", representing the most meritorious original investigation in the physical sciences.

ThE following appointments have recently been made in the Colonial Service: F. H. B. Blackburn, to be agricultural chemist, Barbados; J. V. Harbord, to be agricultural superintendent, British Guiana; T. E. Ryall, to be agricultural officer, Nigeria; J. B. Smart, to be assistant conservator of forests, Kenya; A. Jefferiss, to be chief fruit inspector, Palestine; W. J. Badcock, agricultural officer, Uganda, to be senior agricultural officer, British Solomon Islands Protectorate; W. H. B. Buckhurst, assistant director of lands, mines and surveys, Fiji, to be director of lands mines and surveys, Fiji. 